\title{
'n Interpretasie van die beeld van die brander in Jakobus 1:6
}

H F Stander

\begin{abstract}
An interpretation of the image of the wave in James 1:6
\end{abstract}

In James 1:6 the person who doubts when he prays, is compared with a wave in the sea that is driven and blown about by the wind. It is traditionally believed that the point of the comparison is the instability of the sea waves. Thus he who doubts is like a wave which is driven hither and thither by any chance wind - like a cork floating on the wave. $I t$ is argued in this article that this interpretation does not take cognizance of the structure of the wider context. It is suggested that the point of the comparison is rather the downward movement of the wave: the crest of the high wave dives downwards and at the end the wave completely vanishes.

In Jakobus 1:6 word die persoon wat twyfel wanneer hy bid, vergelyk met "'n brander in die see wat deur die wind aangejaag en voortgesweep word". Die betoog van hierdie artikel is dat die beeld van die brander nie reg vertolk word deur moderne eksegete nie, waarskynlik op grond van die foutiewe vertaling van hierdie teks. Die omgekeerde mag dalk ook waar wees, naamlik dat Jakobus 1:6 foutief vertaal word, omdat die beeld nie reg verstaan word nie. Die huidige vertalings probeer dus bloot om reg te verleen aan 'n reeds foutiewe verstaan van die beeld. Voorts sal daar gepoog word om aan te toon dat die algemene interpretasie van hierdie beeld van die brander ook nie rekening hou met die strukturele opbou en stilistiek van die boek Jakobus, maar in die besonder van die hele perikoop wat oor beproewinge en versoekinge handel nie (naamlik Jakobus 1:1-18).

Dit is merkwaardig dat kommentatore oor die algemeen van mening is dat hierdie beeld eenvoudig is en die interpretasie daarvan sonder enige probleme. Adamson sê byvoorbeeld dat "the interpretation of the marine analogy in this verse is typically simple"1. Ook Dibelius reken dat "the application of the metaphor here is very simple and natural"2. Tog, wanneer 'n mens verskillende kommentare raadpleeg, bemerk 'n mens dat die beeld nie so eenvoudig is nie en dat dit ook nie op heeltemal dieselfde wyse vertolk word nie. Dit is ook interessant om te sien watter aanpassings die kommentatore in die teks maak om die beeld "te laat werk" en te laat inpas by hul interpretasie. 
Die interpretasie wat algemeen voorkom, is dat die mens wat twyfel soos 'n golf op die see is wat doelloos heen en weer oor die wye see gejaag word. Pretorius byvoorbeeld verduidelik die beeld deur te sê "die veranderlike wind bepaal die koers van die gety - een dag met loeiende geweld in een rigting (my kursivering), en die volgende dag met dieselfde drif in 'n totaal teenoorgestelde koers (my kursivering)"3. Hy gaan voort deur te sê dat die mens met twyfel in sy gemoed is dus soos 'n brander wat "magteloos en ankerloos oor die diep waters rondgegooi word (my kursivering) volgens die toevallig heersende aardse omstandighede". Ook Barclay sê dat "if he asks in doubt, his mind is like the broken water of the sea, driven hither and thither (my kursivering) by any chance wind"4. Hierdie interpretasie word ondersteun deur verskeie vertalings van die Bybel. Die 1983Afrikaanse Vertaling van die Bybel, byvoorbeeld, vertaal Jakobus 1:6 soos volg: "... soos 'n brander in die see wat deur die wind aangejaag en heen en weer gedryf word". Die frase "heen en weer" staan glad nie in die Griekse grondteks nie, maar word in Bybelvertalings ingevoeg om die bepaalde interpretasie te ondersteun. In die

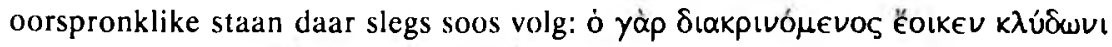

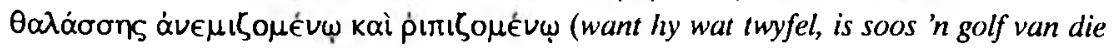
see wat deur die wind gedrywe en voortgesweep word). Verskeie eksegete 5 beroep hul graag daarop dat daar 'n soortgelyke aanwending van hierdie beeld voorkom in

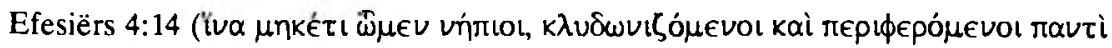

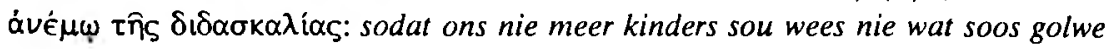
geslinger en heen en weer gedryf word deur elke wind van lering nie...). Dit lyk egter nie of die beeld in Jakobus 1:6 sonder meer verklaar kan word aan die hand van Efesiërs 4:14 nie. In die eerste plek word die kwessie van golwe wat "heen en weer gedryf word" (wat die basis vorm van sommige eksegete se verklaring van Jakobus 1:6) eksplisiet genoem in Efesiërs 4:14. In Louw \& Nida word die betekenis van $\pi \epsilon \rho \iota \dot{\rho} \rho \omega$ in Efesiërs 4:14 byvoorbeeld aangegee as "to carry around from one place to another"6. In Jakobus 1:6, daarenteen, is daar geen woord wat die betekeniskomponent dra van "heen en weer" nie.

Ander eksegete weer is oortuig dat die sleutel tot die verstaan van die

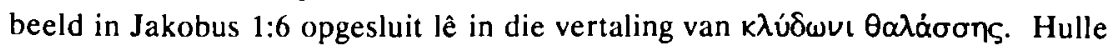
argumenteer dan dat $k \lambda u ́ \delta \omega \nu$ nie met "golf" of "brander" vertaal moet word nie, maar eerder met "rowwe waters" of "storm". Laws skryf byvoorbeeld dat "the classical use as meaning surf or rough water makes better sense in an image of one who wavers and hesitates, tossing about like the surface of water thrown up by passing gusts of wind"7. Ook Hauck redeneer dat $k \lambda u ́ \delta \omega \nu$ as die teenoorgestelde van yoגnum ("kalm, gladde see") gesien moet word. Hy gaan nog verder en soek selfs steun vir die gedagte van "storm" bo "golf" in die woord pırı૦ $\mu$ é $\nu$. Hauck

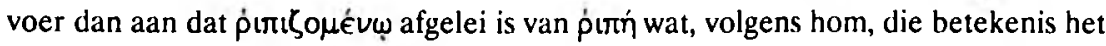


van "storm". Ook Dibelius skryf soos volg: "When one also compares the passages in Philo, Sacr. AC. 90 and Gig. 51, then it becomes likely that k $\lambda \dot{v} \delta \omega \nu$ here does not mean 'wave', but rather 'billowing, surging'. Therefore the doubter is not compared with the wave, but with the restless sea stirred up by the wind"8.

'n Mens kan egter nie anders as om ernstige beswaar te hê teen bogenoemde verklarings nie. In die eerste plek kan daar nie met hierdie etimologiese werkswyse saamgegaan word nie. In die tweede plek is dit onwaarskynlik dat $k \lambda u$ úowv ooit in die Nuwe Testament in die betekenis van "storm" aangewend word (vergelyk byvoorbeeld Louw \& Nida9). In die derde plek is dit nie duidelik waarom "storm" as betekenis vir $k \lambda u ́ \delta \omega \nu$ die beeld beter verduidelik as die betekenis van "golf" of "brander" nie. Moet 'n mens nie maar soos Mußner sê nie dat "ob Jak bei dem gebrauchten Bild mehr an die Brandung oder an das Wogen des Meeres denkt, ist für die Auslegung nicht sonderlich von Belang ${ }^{10 "}$ ?

Die betoog van hierdie artikel is dat die beeld van die brander van die see, hier nie verstaan moet word as die heen en weer en doellose beweging van die golf nie, ook nie as 'n onstuimige storm van 'n rowwe see nie. Veel eerder moet ons hier dink aan 'n hoë brander wat, soos hy voortgejaag en voortgesweep word deur die wind, "kop" ondertoe tuimel en ten einde laaste geheel en al tot niet gaan. Dit is altyd treffend om te sien hoe elke golf, hoe groot ook al, terwyl hy voortgerol word (nie noodwendig "heen en weer nie"), later geheel en al sy volume en krag verloor totdat dit heeltemal "verdwyn". So is die man wat twyfel: Hy begin groot, maar op die ou einde kom daar niks van sy aksie nie. Hy vermag niks (en "verkry niks" volgens Jakobus $1: 7$ ) en alles stort in duie. Vir enigiemand wat naby die See van Galilea gewoon het, sou hierdie beeld duidelik gewees het omdat hierdie see bekend was vir sy groot golwe (vergelyk Matteus 8:24 en Markus 4:37). Ook die Middellandse See, die enigste ware "see" in die streek, kan groot golwe oplewer.

Maar kom ons kyk vervolgens hoe die opbou en die struktuur van die hele perikoop hierdie beeld ondersteun en na vore bring: Die passasie wat handel oor beproewinge en versoekinge strek vanaf vers 2 tot 18 . Hierdie hele gedeelte bestaan onder andere uit 'n hele aantal binêre, maar polêre, eenhede. Elk van hierdie eenhede bestaan dus uit twee elemente wat 'n saak vanuit twee teenoorgestelde perspektiewe bekyk, naamlik die positiewe en die negatiewe. Eintlik is dit niks anders as die twee verskillende kante van dieselfde munt nie. So lees ons in die eerste eenheid (verse 2-4) dat die persoon wie se geloof beproef word, juis vanweë hierdie beproewing sterker aan die ander kant kan uitkom (positief). Aan die ander kant (tweede eenheid: verse 5-8) is dit ook moontlik dat jou geloof deur twyfel geteister kan word en dat jy dan soos die golf van die see voortgejaag word en tot niet gaan (negatief). In die tweede eenheid (verse 9-11) lees ons dat die broeder wat gering is, moet roem in sy hoogheid (positief), terwyl die ryke weer moet roem 
in sy geringheid (negatief). In die derde eenheid (verse 12-15) sê Jakobus dat diegene wat die toetsing deurstaan het, die kroon van die lewe sal ontvang (positief), terwyl daar weer ander is wat tydens die toetsing deur hul eie begeerlikhede tot val kom en sodoende die dood ontvang (negatief).

Wat verder opvallend is in hierdie drie eenhede, is dat elk van hulle nie slegs uit twee polêre elemente bestaan nie, maar elk van die drie positiewe elemente vertoon 'n stygende lyn, terwyl elk van die negatiewe elemente weer 'n dalende lyn vertoon. In die eerste positiewe element (verse 2-4) lees ons dat beproewing lydsaamheid bewerk, en dat lydsaamheid weer tot volle verwerkliking moet kom, sodat die mens volmaak en sonder gebrek kan wees. Die mens wat derhalwe hierdie beproewing suksesvol deurstaan het, het "opbeweeg" tot hierdie hoër doelwit. Let daarop dat hierdie "groeiproses" ook stilisties ondersteun word. Die outeur maak gebruik van die $k \lambda \hat{\imath} \mu \alpha \xi$ ("leer") wat 'n baie populêre stilistiese tegniek was waardeur die laaste woord van 'n frase die eerste woord van die volgende frase geword het. In die tweede positiewe eenheid (vers 9) is dit die geringe man wat kan "opbeweeg" en in sy hoogheid kan roem. In die derde positiewe eenheid (vers 12) is dit die man wat die versoeking verdra het, wat as sy hoogste goed die kroon van die lewe sal ontvang.

Maar, soos reeds gesê, word die negatiewe elemente met dalende beelde voorgestel: Die ryke moet roem in sy geringheid en sy kwynende en tanende belangrikheid word treffend voorgestel met 'n beeld van 'n plant wat geleidelik verdor, en uiteindelik val sy blom af en op die ou einde is al sy sierlikheid weg (verse 9-11). In die derde negatiewe eenheid (verse 13-15) lees ons weer van 'n mens wat deur sy begeertes meegesleur word, en van begeertes wat sonde voortgebring het, en van sonde wat op die dood uitgeloop het. Let daarop dat die stelselmatige trapsgewyse aftakelingsproses in laasgenoemde eenheid weer eens stilisties ondersteun word deur gebruikmaking van die tegniek wat as $k \lambda \hat{\imath} \mu \alpha \xi$ bekend gestaan het. En bogenoemde negatiewe prosesse is presies wat ook met die man gebeur wie se geloof deur twyfel geteister word en wat met die golf van die see vergelyk word: ons weet tog almal wat met so 'n brander gebeur wanneer dit deur die wind voortgedryf word: dit breek en op die ou einde bly daar niks daarvan oor nie (net soos daar ook niks van die plant oorgebly het nadat dit verdor het nie). Dalk is dit ook nie vergesog om te beweer dat die trapsgewyse (klimaktiese) groeiproses van die een wie se geloof beproef word, en die trapsgewyse aftakelingsproses van die plant wat eers verdor, en daarna sy blom verloor, en die trapsgewyse ondergang van die mens wat val voor versoeking, ook te sien is in die "trapsgewyse" vernietiging van die golfbeweging op die see nie!

'n Mens sou die positiewe en die negatiewe prosesse in die eerste deel van Jakobus soos volg kon voorstel: 


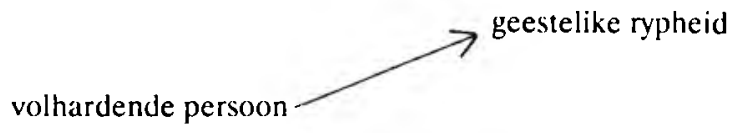
twyfelende persoon
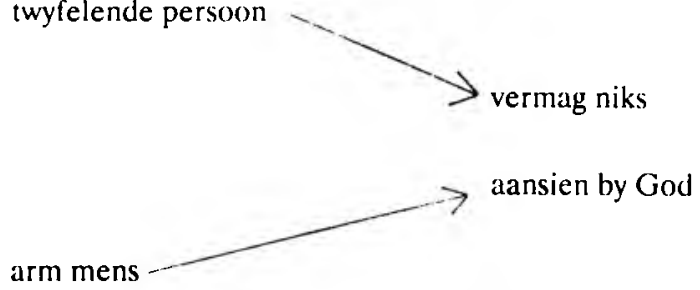

ryk mens
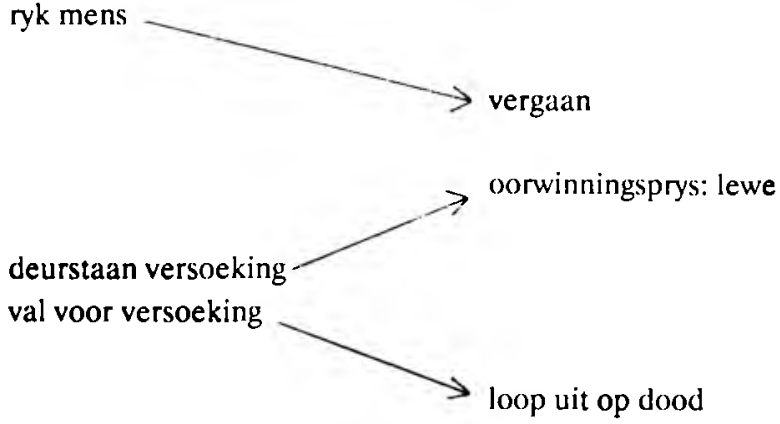

Bogenoemde wyse van argumentasie is ook tipies Semities. Ons kry dikwels in die Ou Testament die argument dat daar 'n totale omkering van posisie plaasvind, gewoonlik met die bedoeling dat Gód hierdie omkering bewerkstellig (vergelyk byvoorbeeld 1 Samuel 2:3-10). Dit geld veral van verse 9-10 hierbo. Voorts word hierdie deel ook gekenmerk deur talle antiteses, wat ook 'n populêre stylfiguur in die antieke tyd was, insluitende in die Semitiese wêreld. Bogenoemde analise is dus volkome in lyn met die algemene siening van eksegete dat die Jakobusbrief talle kenmerke dra van 'n "Joodse Christendom". Talle ander Joodse karaktertiekke wat in die brief voorkom, het sommige eksegete selfs al laat gis dat die Jakobusbrief teruggaan op 'n antieke Joodse traktaat11.

Kommentatore ${ }^{12}$ sien nie slegs in Efesiërs $4: 14$ 'n beeld wat baje ooreenkom met die beeld in Jakobus 1:6 nie, maar ook in Jesaja 57:20 ("Maar die goddeloses is soos die onstuimige see wat nie tot rus kan kom nie en waarvan die golwe aanhou om slyk en modder uit te stoot"). Ons het reeds hierbo gesien dat die beeld van Efesiërs 4:14 nie sonder meer op Jakobus 1:6 van toepassing gemaak kan word nie. Maar ook die beeld in Jesaja word op 'n heel ander wyse aangewend. Dit is wel waar dat dit in Jesaja 57:20 ook die uiteinde van die golf is wat die negatiewe 
konnotasies dra, maar die punt van ooreenkoms (tertium comparationis) tussen die goddeloses en die onstuimige see is hier dat die goddeloses keer op keer, soos aanhoudende golwe, hul bose dade verrig. Dit is interessant om daarop te let dat die see deur die hele Skrif gesien word as 'n mag wat vyandiggesind is teenoor God (dalk vanweë die verskrikking walt die see vir die antieke mens ingehou het). Dit verklaar ook waarom die see in beelde gebruik word met negatiewe betekenisse: Die goddelose is net so aanhoudend soos die golwe van die see (Jesaja 57:20); mense word soos golwe heen en weer geslinger deur die dwaalleer van valse leraars (Efesiërs 4:14); die mens wat twyfel wanneer hy bid vermag niks nes 'n hoë golf wat "breek" en betekenisloos ondertoe geslaan word deur die wind.

Maar ons moet ook kyk hoe Jakobus hierdie beeld verder toepas in

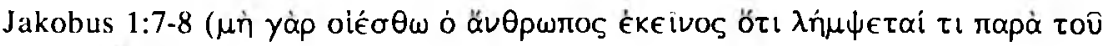

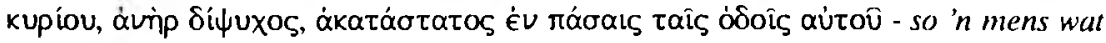
altyd aun die twyfel is en onbestendig is in al sy doen en late, moet nie dink dat hy iets van die Here sal ontvang nie). Op grond van die tradisionele interpretasie van

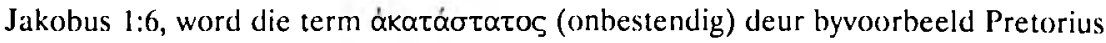
soos volg verduidelik: "dit is onbestendig: dit swenk heen en weer (my kursivering) tussen teenstrydige keuses en maak dit onmoontlik om op enige van sy baie lewenspaaie tot 'n duidelike beslissing te kom oor lewensbepalende sake"13. Dit gaan egter ook hier in hierdie beeld nie oor die "heen en weer" van die golwe nie. Dit gaan daaroor dat die golwe deur invloede van buite (naamlik die wind) voortgerol word - dit is nie stewig vasgeanker nie (om nog 'n beeld uit die wêreld van die see te gebruik). Louw en Nida gee juis die betekenis van die woord $\dot{\alpha} k \alpha \tau \dot{\alpha} \sigma \tau \alpha \tau o \zeta$ aan as "uncontrolled". Die twyfelende mens is dus ankerloos en beheer nie self sy eie bewegings nie, maar word deur eksterne invloede (gesimboliseer deur die wind) voortgedryf. Die Good News vertaal verse 7-8 goed met "a person like that, unable to make up his mind and undecided in all he does, must not think that he will receive anything form the Lord". Net soos daar op die ou einde niks oorbly van die golf nie, loop ook hierdie twyfelende mens se aksies op niks uit (net soos dit ook gebeur het met die verwelkende blom). Jakobus sê dit natuurlik eksplisiet: so 'n mens moet nie dink dat hy iets van die Here sal ontwang nie!

Alhoewel al die kommentare nog altyd iets wou maak van die "heen en weer" (wat nie in die teks staan nie) of van die "storm" (wat op 'n foutiewe vertaling van die Griekse woord $k \lambda u ́ \delta(\omega \nu$ berus), is daar tog een eksegeet wat meer as vyftig jaar gelede reeds die beeld in Jakobus verduidelik het in terme van 'n golf of brander wat voortgedryf word en wat uiteindelik tot niet gaan. Grosheide het in 1935 reeds soos volg geskryf: "De man, die twijfelt, is als de hooge baar in de ruwe zee, vergelyk Jesaja 57:20. Deze mist alle vastheid, de wind stuwt hem op en jaagt hem verder; hij wordt topzwaar en schuimend glijdt de kop naar beneden"14. 
Grosheide vat hierdie heeld mooi saam deur daarop te wys hoe 'n persoon wat twyfel soos 'n hoë brander neerstortend tot niet gaan. Ongelukkig het Grosheide nie sy interpretasie verantwoord nie, en dit is dalk ook die rede waarom sy vertolking nie later deur ander eksegete nagevolg is nie. Die doel van hierdie artikel is dan juis om Grosheide se verduideliking van die beeld te begrond.

Ten slotte: Die tradisionele vertolking van die beeld van die brander in Jakobus 1:6 berus daarop dat die element "heen en weer" in die teks ingevoer moet word, terwyl daar eintlik geen gronde vir so 'n invoeging bestaan nie. Daarenteen word die interpretasie wat in hierdie artikel voorgestaan word, gerugsteun deur "merkers" in beide die struktuur en die intioud. Daarom lyk dit tog of laasgenoemde moontlike vertolking meer waarskynlik is as die tradisionele.

\section{NOTAS:}

1 J B Adamson, The Epistle of James, Grand Rapids 1976, 58.

2 M Dibelius, Der Brief des Jakobus (vertaal deur M A Williams), Philadelphia 1976,81 .

3 E A C Pretorius, Die Brief van Jakobus, Kaapstad 1988, 36.

4 W Barclay, The Letters of James and Peter, Edinburgh 1976, 46. Ander eksegete wat hierdie beeld op soortgelyke wyse interpreteer, is F Grünzweig, Der Brief des Jakobus, Wuppertal 1973, 34; M Holland, Jakobus-Briefe, Neuhaussen-Stuttgart 1988, 21; P P A Kotze, Die Brief van Jakobus, Kaapstad 1990, 78; E L Smelik, De Brief van Jakobus: De Stiefapostel, Nijkerk $1963,23$.

$5 \quad$ Vergelyk byvoorbeeld L. F Hauck, Der Brief des Jakobus, Leipzig 1926, 46; S Laws, A commentary on the Epistle of James, London 1980, 57; F Mußner, Der Jakobusbrief, Freiburg, 70; F Schnider, Der Jakobusbrief, Regensburg 1987, 32-33; The Interpreter's Bible, New York, 24.

6 J P Louw \& E A Nida, Greek-English Lexicon of the New Testament, New York 1988, 206.

$7 \quad$ Laws, $a w, 57$.

8 Dibelius, $a w, 81-82$; vergelyk ook Adamson, $a w, 58$.

9 Louw \& Nida, $a w, 171$.

10 Mußner, $a w, 70$.

11 S Laws, "James, Epistle of", The Anchor Bible Dictionary, New York 1992, 624. 
12 Vergelyk Dibelius, a w, 81; F W Grosheide, De Bricf van Jakobus, Kampen 1935, 17; Smelik, $a w, 23$.

13 Pretorius, $a w, 36$.

14 Grosheide, $a w, 17$. 